\title{
Building a resilient infrastructure: challenges of rural transportation in Soba Local Government Area, Kaduna State, Nigeria
}

\author{
Abdulkadir Muhammed Yahaya ${ }^{1 *}$, Hajara Salahudeen ${ }^{2}$, Dauda Zubairu ${ }^{3}$ \\ Geography Department, Federal College of Education, Zaria, Kaduna State, Nigeria ${ }^{{ }^{*}}$ \\ Nigeria Institute of Transport and Technology, Zaria, Kaduna State, Nigeria ${ }^{2,3}$ \\ abdulkadirmuhammed2@gmail.com
}

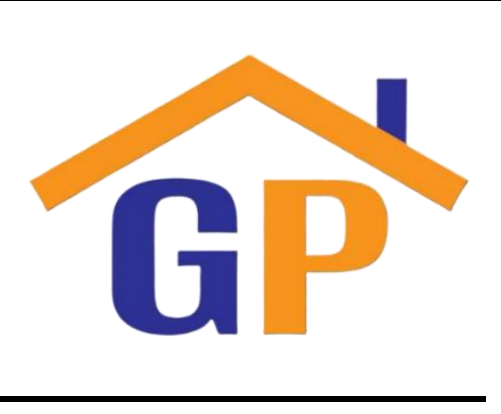

Article History

Received on 14 January 2021

Revised on 17 April 2021

$2^{\text {nd }}$ Revision on 21 April 2021

Accepted on 22 April 2021
Abstract

Purpose: Despite the economic importance of rural transportation, it is often being neglected. This study is aimed at identifying the challenges of rural transportation in the Soba Local Government Area to recommend measures for tackling them.

Research methodology: Both interview and observation methods were applied in data collection and purposive sampling was adopted in choosing rural areas covered by the study. However, 140 interviewees were asked from five areas chosen. The interviewees were transporters, commuters and other stakeholders in rural transportation. Descriptive and inferential techniques were used in data analysis.

Results: The results revealed that road conditions were in a deplorable state, about $39 \%$ of interviewees considered them bad and only $25 \%$ said they were good. About $43 \%$ of the interviewees said transport fare was expensive. About $41 \%$ of vehicles used were in bad shape, $84 \%$ of the interviewees said passengers often spend more than 30 minutes to get a vehicle. The result also showed that there was a significant relationship between good transportation network and economic development.

Limitations: The scope of the study should have been wider to cover the whole eleven political wards of the local government area. The sampling method used might not necessarily give a true reflection of what happens.

Contribution: Rural transport contributes immensely to the development of the world. It creates jobs, access to markets and infrastructure. This study is consistent with Sustainable Development Goals (SDGs) goal 9 and 11. Which are aimed at building resilient infrastructure and settlements.

Keywords: Local, Government, Area, Rural, Transportation

How to cite: Muhammed, A. Y., Salahudeen, H., \& Zubairu, D. (2021). Building a resilient infrastructure: challenges of rural transportation in Soba Local Government Area, Kaduna State, Nigeria. Journal of Governance and Accountability Studies 1(1), 69-82.

\section{Introduction}

Rural transportation is an aspect of a transport system that cannot be joked. Rural transport like urban, requires infrastructure that deals with connectivity, and connectivity in turn improves mobility and also rural standards of living (Economic and Social Commission for Asia and the Pacific [ESCAP] and UN, 2019). Rural transportation is carried out on rural roads and it means different things to different people. However, They are roads typically organized, built and maintained by the rural local governments in the areas under their control and influence. They include among others: Forest roads, canal roads, and village roads can also be placed here. There are researches that placed "Low- 
Volume Rural Roads" (LVRR) as roads with average carrying capacity of 1000 vehicles per day or less, whether they are tarred or untarred pathways (Faiz, Faiz, Wang and Bennet, 2012).

Banjo, Gordon and Riverson (2012) see rural roads as those connecting settlements of less than 2000 to 5000 people to each other or to advance classes of roads, market areas and urban centers. However, such population-based classification systems are less useful in the Nigerian and African context because rural population sizes are not the same from one country to another. Thus, rural roads are all roads in rural areas that do not fall within trunk A (Federal road) or trunk B (State road). Suffice to say, such rural roads that hold the key to additional economic growth in many rural areas are being impeded by the failure to significantly improve it to aid the transportation system and to provide adequate connectivity. Yap (2019) observes that in peri-urban areas, private real estate developers may invest in roads connecting their new housing developments to primary roads, but rural people must rely on the government, which often takes much longer to build secondary and tertiary roads. Therefore, the extent to which rural areas can benefit depends on the quantity and quality of transport infrastructure and ease of connectivity to new employment opportunities and markets.

In addition, most of the world's poor live in rural areas isolated by distance, terrain and poverty from employment and economic opportunities, markets, healthcare and education facilities (Starkey and Hine, 2014). The provision of rural accessibility is seen as the distance to all-season roads and transport services and includes the distance to market and basic services, as well as the critical initial link from agricultural production areas. The provision of affordable, reliable, and inclusive rural transport infrastructure and services is at the heart of rural access (United Nations Centre for Regional Development, 2017). Because of that, Perz, Xia and Shenkin (2014) suggest that increasing the connectivity between rural and urban areas through transport infrastructure can help to mitigate the effects of isolation and provide interaction connectivity; that is, the ties between rural and urban centers, including social and economic interaction.

According to World Bank (2006) there is a strong correlation between reducing poverty and improved rural access, which is achieved through connectivity. For example, in Viet Nam rural access improved significantly from an average of 76 percent to 84 percent at the provincial level during 2002 to 2004 and the incidence of poverty also dropped significantly from an average of 41 percent in 1999 to 24 percent in 2004 at the provincial level. Despite that, low density of demand for transport, poor quality infrastructure poor diversity of vehicle types, uncompetitive transport markets and inadequate government intervention are some of the major problems of rural transportation (Rural Travel and Transport Program, 2001). The United Nations (UN) integrated the provision of rural roads in its 17 Sustainable Goals to improve the connectivity of human settlements and build resilient infrastructure as Goals 9 and 11, respectively.

In addition, the manifestation of rural transport challenges is enormous; however, many attempts were made in other areas to identify transport problems and solutions through research at least. Nevertheless, in the Soba Local Government Area of Kaduna State, Nigeria, no such effort was made hence the conception and development of this study. Therefore, this study aimed to identify the challenges of rural transportation in the Soba Local Government Area to recommend measures for tackling them.

\section{Objectives of the study}

i. identifying road characteristics, conditions and major rural transport terminals in the study area

ii. identifying types of vehicles used and conditions of vehicles used for transport services in the study area

iii. examining the cost of conveying goods to the market in the study area in comparison with urban price 


\section{Research hypothesis}

For the purpose of this study, this hypothesis was formulated:

There is no significant impact of a good transportation network with economic development in the Soba Local Government Area of Kaduna State.

\section{Literature review}

\subsection{Conceptual framework}

\subsubsection{Connectivity}

This means to link up people or to connect them. This link-up can either be physical as in transport or non-physical as in communication (ESCAP, 2019; UNCRD, 2017). Rodrigue, Comtois and Slack (2017), however, see connectivity differently as it is expected to be looked at whether it links up people directly or indirectly. Connectivity can be broadly categorized into three, namely: macro level connectivity network, meso level connectivity network and micro level connectivity network. These three are related or have a connection at different levels. For example, the vertical transport infrastructure connectivity represents connection among micro level, meso level and macro level infrastructure networks. This links up village roads to regional road and of course international networks. In addition, some services are only provided at their levels without any connection or relation. An example of such services is highway vehicles that operate only on highways (ESCAP, 2019; UNCRD, 2017).

Furthermore, macro infrastructure and micro nodes assume that transport services move in sequential order. In reality, this might not work, but there is some connection with the sequential ordering because access to macro level transport is only possible through micro nodes such as motor parks, local markets, commuter's venues and so on. Macro node infrastructure such as railways, dry pots, and international boundaries surrounding rural areas is accessed only through micro nodes. Thus, micro and macro levels and nodes are inseparable (ESCAP, 2019; UNCRD, 2017).

\subsubsection{Rural transport infrastructure}

Rural transport infrastructure covers many aspects of transport, which sometimes pass through trunk A roads (federal roads) and trunk B (state roads), but it is actually trunk C roads (local roads).

\subsubsection{Rural roads}

They are roads normally organized, built and maintained by the rural local governments in the areas under their control and influence. They include among others: Forest roads, canal roads, and village roads that can also be placed here. Some researchers placed "Low-Volume Rural Roads" (LVRR) as roads with an average carrying capacity of 1000 vehicles per day or less, whether they are tarred or untarred pathways (Faiz, Faiz, Wang and Bennet, 2012).

\subsubsection{Transport nodes}

This connects places, areas, people and functions. They can have essential functions such as high schools, healthcare services centers, administrative centers, sports centers, places of production and supply, among others. Transport nodes, in short, are places where the transfer of goods, services and even passengers takes place. This includes; the motor parks, train stations, seaports, warehousing and logistic centers, and important points where people meet for movement.

\subsubsection{Rural transport services}

Rural transport services are transport services that include passenger services, commercial freight services, public transport services and some rural and urban services. The term covers both rural and urban services because some services taken from rural areas as places of origin end at urban areas as places of destination (Starkey \& Kaumbotho, 2000 in ESCAP, 2019; UNCRD, 2017).

\subsubsection{Dimension of transport}

There are three general concepts of transport geography: transport network, transport demand, and transport system. 


\subsubsection{Transport network}

This considers the spatial structures and organization of transport infrastructure and terminals. It also looks into how these infrastructures are planned and organized. In short, it looks into either terminal or connecting facilities. The terminals that enable us to starts movements from one place to another include; the bus stops, airports, rail stations motor parks, etc. While the connecting facilities are roads, rail lines, walkways, cable ways, and actual mechanisms or items that are used in movements of vehicles (Rodrigue, Comtois and Slack, 2017).

\subsubsection{Transport demand}

This considers the spatial demand for transport services as well as the modes uses to support these movements. The demand for transport and the subsequent initiation of the movement results in flows. These flows may be a journey to work or general intra-movements, inter-city movement, interregional movement, or, at best, physical distribution. Consequently, these different flows result in the different patterns that interest transport geographers (Rodrigue, Comtois and Slack, 2017).

\subsubsection{Transport system}

This considers the complex relationships between the networks, the demands and space. The totality of these relationships must be analyzed within the context of the socio-political and socio-economic context of a given region which brings us to the hinterland issues (Rodrigue, Comtois and Slack, $\underline{2017)}$.

\subsubsection{Flows in a transportation system}

Transport demand is usually a derived demand because we require a vehicle due to demand for some other services. Put it differently; we often move from one place to the other in order to satisfy some needs, such as the demands for goods. Over time, the various demands for goods and services generally result in the generation of flows. These flows may be a form of the movement of goods, passengers and messages. Flows have different types. They are as follows:

\subsubsection{Point to point flows}

This is a flow from the point origin to the point of destination and could depend on the level of aggregation and or disaggregation. Thus, a town could be regarded as a point and even a town with various points.

\subsubsection{Area to area flows}

This is from the point of origin to the point of destination such as interstate movement like form Kaduna State to Niger State to Kwara State, Lagos State or from any Nigerian State to another State.

\subsubsection{Distribution flows}

This is the movement from one point of origin or few points of origin to several points of destinations. It concerns the distribution of freights to satisfy consumptions and manufacturing requirements. They are more often a concern with distribution centers and retail outlets.

\subsubsection{Collection flows}

This involves many points of origin and few points of destination-for example, cotton supply. Depending on the level of aggregation and disaggregation, some other types of flows can be identified in an urban movement system.

\subsubsection{Regular movement}

This is the most common type of movement, which includes; regular movement, which is somehow involuntary movement involving commuting between places of residence and places of work. They are highly cyclic since they are unpredictable and reoccurring on a regular basis in most cases.

\subsubsection{Tourist movement}

This type of movement is essential to cities that have historical and recreational features and therefore involve interactions between such tourists' sites and the hotels. 


\subsection{Theoretical framework}

There are many theories that deal with space, transport and connectivity. Some of the notable ones include spatial interaction model, gravity model, Reilley's model and so on. The spatial interaction model, gravity model and Reilley's model are discussed here.

\subsubsection{Spatial interaction model}

The spatial interactions model seeks to explain spatial flows. As such, it is possible to measure flows and predict the consequences of changes in the conditions generating them. When such attributes are known, it is possible for example, to better allocate transport resources such as highways, buses, airplanes, or ships since they would reflect the transport demand more closely. The basic assumption concerning many spatial interaction models is that flows are a function of the attributes of the locations of origin, the attributes of the locations of destination and the friction of distance between the concerning origins and the destinations. The general formulation of the spatial interaction model is as follows:

$T i j=f(V i W j S i j)$. Where;

$T i j=$ interaction between location $i$ (origin) and location $j$ (destination). Its units of measurement are varied and can involve people, tons of freight, traffic volume, and so on. It also relates to a time period such as interactions by the hour, day, month or year.

$V i=$ attributes of the location of destination $i$. Variables often used to express these attributes are socio-economic in nature, such as population, number of jobs available, industrial output or gross domestic product.

$W j=$ attributes of the location of destination $j$. It uses similar socio-economic variables than the previous attribute.

Sij $=$ attributes of separation between the location of origin $i$ and the location of destination $j$. Also known as transport friction. Variables often used to express these attributes are distance, transport costs, or travel time.

The attribute of $V$ and $W$ tend to be paired to express complementarities in the best possible way. For instance, measuring commuting flows (work-related movements) between different locations would likely consider a variable such as working-age population as $V$ and total employment as $W$.

A spatial interaction involves the movement of goods, messages or information and passengers between two locations or among places. This description implies that interaction tends to consider the number of flows between any two points or more. Indeed, several factors are responsible for such interactions. It is the desire for answers as to why interactions such as flows and linkages take place that led Edward Ullman in 1956 to formalize the factors that affect interactions as Ullman triad.

According to Ullman, the basis of interaction can be summarized into three, namely: complementarity, intervening opportunity and transferability.

\subsubsection{Complementarity}

The concept of complementarity tries to visualize a situation where supply should be in one area and demand may be in another area or location. However, it is important to note that the demand and supply conditions may sometimes be in terms of services. Sometimes complementarity may be potential or latent in nature; the former refers to a setting where although demand and supply conditions are satisfied, no interaction occurs between and among such locations. i.e. such places can interact but are not yet doing so. Thus, the actual interaction is potential and is yet to take place with respect to the latter; definite conditions that could generate interactions and flows are present but for now, actual demand had not taken place. In other words, this is a situation where the conditions necessary for commodity production have been satisfied at present, but there is no production at the moment. 


\subsubsection{Intervening opportunity}

By intervening opportunity, we are simply referring to an alternative supply point between locations. The basic idea is that it is either nearer or cheaper to purchase an item in such an alternative supply point or area. Put differently; it is an area of competing supply point to an existing supply source which will reduce the opportunities of a given supply point. For example, the opportunity of the Zaria market having a significant threshold of buyers has been reduced by the intervening potential of Kano markets from Zaria.

\subsubsection{Transferability}

This is the distance factor which could be translated in terms of the cost of transport. All things being equal, the lesser the cost of transport and/or the lesser the distance separating two locations, the more the interactions. For example, the interaction between Zaria and Kano both in northern Nigeria and both in terms of distance apart and cost of transportation, compared to the interaction between Zaria and Lagos, a southern Nigeria which is more expensive and has a long distance apart. Additionally, it could also be in terms of the perceptual distances between locations.

\subsubsection{Gravity model}

The gravity model is the most common formulation of the spatial interaction method. The gravity model is named after the law of gravity formulated and developed by a British scientist, Sir Isaac Newton. It is applied in many different fields such as migration, commodity flows, traffic flows, commuting, and evaluating boundaries between market places. According to the law, the attraction between two objects is proportional to their mass and inversely proportional to their respective distance. As a result, the gravity model takes into consideration the sizes of locations and the distances that separate them. The model simply states that; the sizes of two locations vary with their interactions while distances separating two locations vary inversely with their interactions. Thus, the greater the population of two centers, the greater their interactions and also the more significant the distance separating two places, the lesser their interactions. The model is given as;

$I i j=k P i P j / d i j . \quad$ Where;

$I i j=$ interactions between locations $i$ and $j$

$\&=$ proportional to

$P i$ and $P j=$ Importance of the location of origin $i$ and the location of destination $j$.

$d i j=$ distance separating location of origin $i$ and location of destination $j$.

$k=$ is a proportionality constant related to the rate of event. For instance, if the same system of spatial interactions is considered, the value of $k$ will be higher if interactions were given importance for a year comparatively to the value of $\mathrm{k}$ for one week.

\subsubsection{Reilley's model}

Reilley's model applies to the principles of the gravity model to delineate market areas. Reilley stated that;

Two centers attract trade from intermediate places approximately in direct proportion to the square of the distances from these two centers to the intermediate place. Reilley's model is given as;

$B a / B b=P a / P b(D b / D a)^{2}$. Where;

$B=$ represents the proportion of retail business from the intermediate city attracted to city $a^{\prime}$ and city $b^{\prime}$

$D=$ distance from the intermediate city. 
In fact, the same model can be applied to any shopping behavior (where the size of the supermarket and area or town or city is known) within a particular city by imaging that $a^{\prime}$ and $b^{\prime}$ represents supermarkets or shopping centers and there is a neighborhood located between them.

\subsection{Review of previous works}

There are many studies conducted on rural transportation. Some of them are highlighted in this study. Vasconcellos (1997) examined the impact of rural transport on children's access to education in Sao Paolo, Brazil. The study revealed that many children drop out of school due to the long distance from home to schools without efficient transport provision. The study made recommendations on how best they can be addressed using the already existing policies in the country.

Mc Kenna (2006), analyzed rural transportation and rural isolation of senior citizens in the Meath region. Older adults' mode of transport was identified in Meath and South Cavan. The study found that Flexi bus that older adults used in Meath was preferred and using such a mode of transport was a delightful experience.

Cook etal (2017) studied the impact of rural transport in achieving Sustainable Development Goals (SDGs) in some Asian countries. The study finding revealed that rural transport can help achieve more than half of the 17 Sustainable Development Goals as most of the goals are connected with rural transportation.

In Nigeria, Aderamo and Magaji (2010) used surveys and mapping to generate data on the impact of the road in locations of facilities in the Edu Local Government of Kwara State. The results showed that there was a significant relationship between poor road conditions and public facilities in the study area. The study recommended rehabilitating the poor roads and provision new ones where there were none.

Adedeji etal (2014) assessed the impact of road transport on rural development in the Obukun Local Government Area of Osun State. The study used questionnaires to acquire data from respondents. The result revealed that there was inequality in the provision of road infrastructure and rehabilitation of roads in the study area. Thus, disparity exists between areas with good road networks and areas without them. The result also revealed that poor transport networks affect agricultural activities in rural areas, thereby increasing the poverty level in the area as it is also an agrarian or a rural local government area. The study recommended that equality be maintained in road provisions and rehabilitations and called for a community effort to renovate and even build some roads in the study area and beyond.

\subsection{The study area}

Soba is an agrarian Local Government Area in Kaduna State with headquarters in Maigana. The Local Government Area has an area of 2,234 $\mathrm{km}^{2}$. It is bounded to the North by Kudan, Makarfi and Ikara Local Government Areas, to the East by Kubau Local Government Area, to the South by Kauru and Igabi Local Government Areas and to the West by Igabi, Zaria and Sabon Gari Local Government Areas. See Figure 1. There are eleven (11) political wards in the Local Government Area, namely: Soba, Maigana, Turawa, Gamagira, Rahama and Dan'wata. Others are Garun, Kinkiba, Richifa, Kwassallo, and Gimba.

The local area has a lot of rural markets, which include: Tudun Saibu Market, Soba Market, Dinya Market, Turawa Market, Rahama Market, Gamagira Market and Maigana Market, but to mention some. There is also a Fagachi Forest Reserve where lumbering is practiced and Matari Dam is used for extensive irrigation farming, which are enormous potentials for the Local Government Area. The area has a federal road (trunk A) cutting across it from Zaria to Jos, Plateau State (two essential towns in northern Nigeria. There are many state roads (Trunk B) and local roads (Trunk C) (Works Department Soba LGA, undated). See Figure 2. 


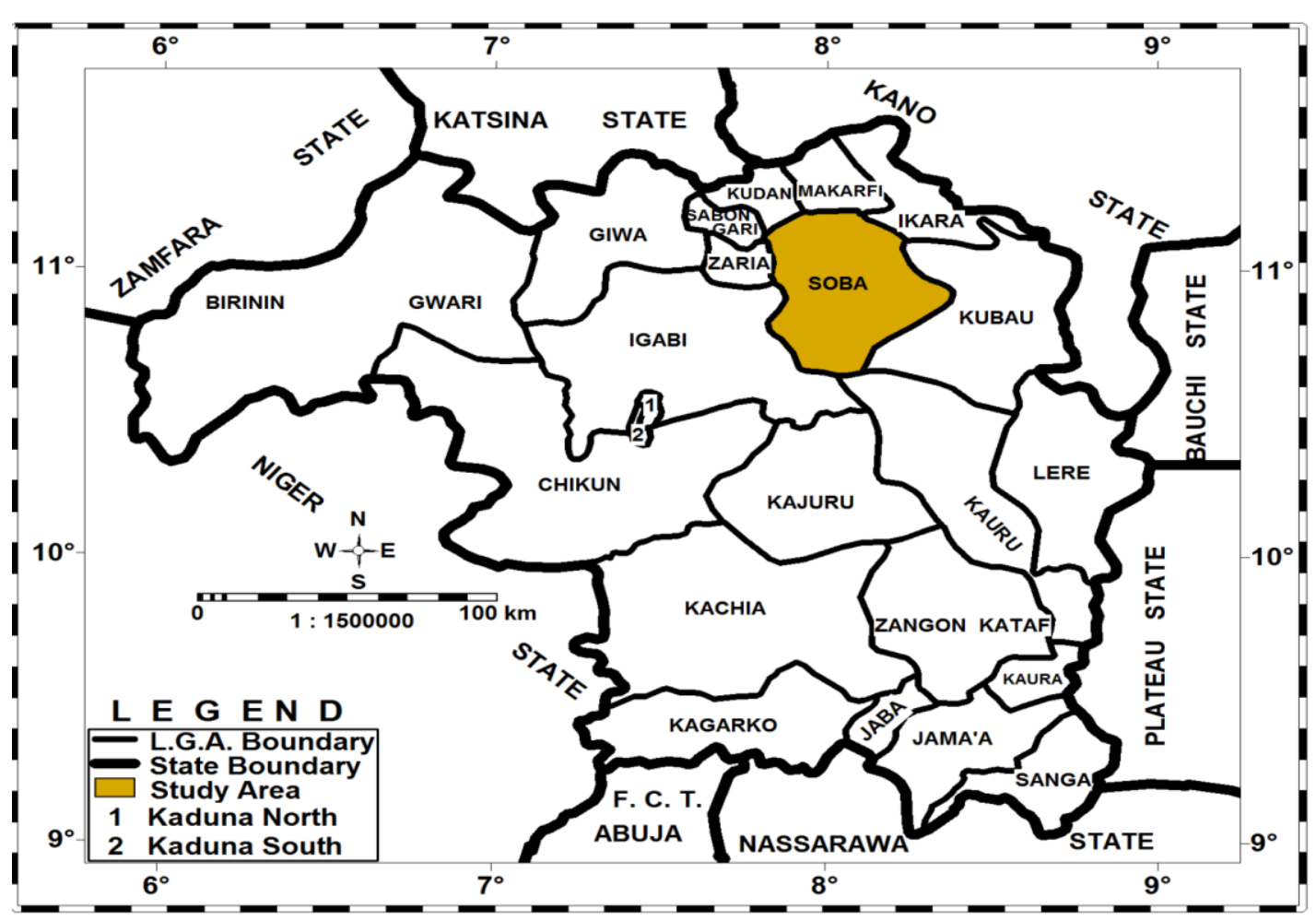

Fig 1: Kaduna State Showing Soba Local Government Area.

Source: Geography Department Federal College of Education Zaria.

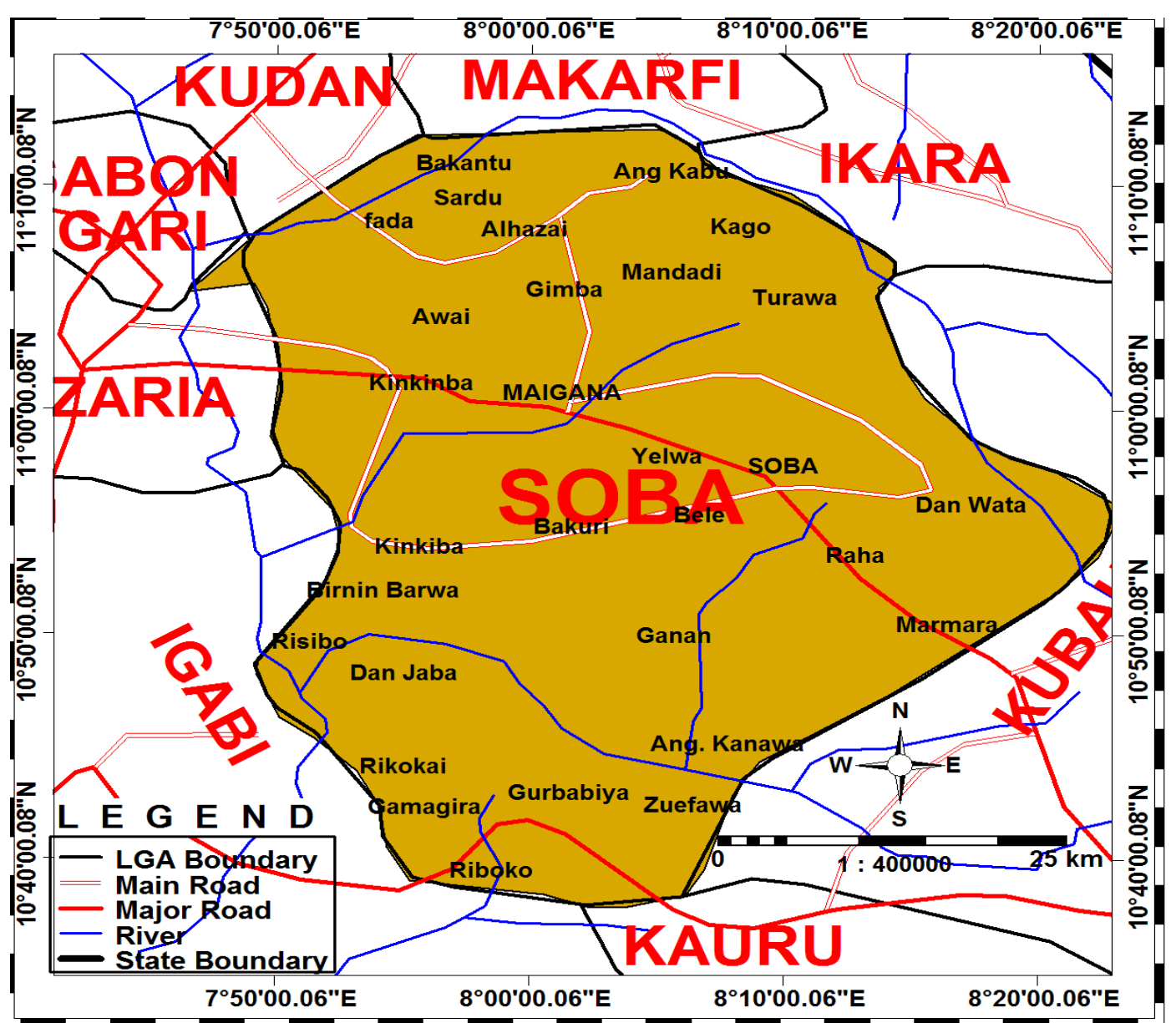

Fig. 2: Soba Local Government Area Showing the Road Network

Source : Department of Geography, Federal College of Education, Zaria. 


\section{Research methodology}

\subsection{Types of data required}

The following types of data were collected:

1. Road characteristics and conditions.

2. Trips between major transports terminals or wards to major rural market.

3. Cost of conveying goods to the market in comparison with urban price.

4. Condition of vehicles use for transport services.

5. Types of vehicles used.

The data on road characteristics and conditions was collected through a schedule of observation and interviews. Data on the distance between major transport terminals to the primary market was collected through interviews. More so, data on cost of conveying goods to the market in comparison with urban was also collected through interviews. Also, data on the condition of vehicles used for transport service was collected through interviewing motorists and transporters. Finally, data on road user's perception of road conditions was collected using observation and interviews.

\subsection{Sources and method of data collection}

Primary data was collected from roads using observation and interview, while secondary data was sourced from past thesis, journals, internet, seminar papers, and records from Soba Local Government works department.

Observation Method was used for data collection besides interview, which complements the data collection process. The interview was administered to the head of household, rural dwellers, farmers, marketers, community leaders, and government agencies. There were also interviews conducted with commuters, motorists, passersby and some stakeholders regarding the challenges of rural transportation in the Soba Local Government Area in order to get the first-hand information.

\subsection{Sampling technique and population selection}

Purposive sampling was adopted for the selection of five from eleven wards used for the study. The criteria adopted for the selection was proximity to the largest market in the Local Government Area, which is Soba market. Thus, the wards of Rahama, Danwata, Maigana, Kinkiba and Turawa were selected. See Figure 2.

On population, 140 interviewees were selected from the population of 220 transporters (Krejie and Morgan, 1970). Eleven wards were prepared, and five were purposively selected interviewing 28 people each, making it a total of 140 interviewees.

\subsection{Data analysis}

The data were analyzed using the descriptive statistical method. Tables of frequency and percentages from generalizations were made. In addition, Pearson moment correlation was used inferentially to test the hypothesis.

\section{Results and discussion}

Table 1. Roads condition

\begin{tabular}{crrr} 
Road nature & Frequency & Percent & Cumulative Percent \\
\hline Good & 36 & 25.7 & 25.7 \\
Fair & 49 & 35.0 & 60.7 \\
Bad & 55 & 39.3 & 100.0 \\
Total & $\mathbf{1 4 0}$ & $\mathbf{1 0 0 . 0}$ & \\
\hline
\end{tabular}

From Table 1, a total of 140 people were interviewed on the condition of roads across the Local Government Area. The trunk A and trunk B roads are in deplorable conditions, while most trunk C roads are untarred. Little wonder that only $36(25.7 \%)$ interviewees say the roads are good. The 
highest percentage 39.3 (55), say the roads are bad. This seriously affects the economy because the area produces thousands of tons of maize, guinea corn, millet, rice and tubers like yam, potato, cocoyam and cassava all year round (rainy and dry season). If they had good roads, there would have been many warehouses to help store excess produce, create more jobs and ensure a continuous flow of these goods year-round.

Table 2. Terminal

\begin{tabular}{crrr} 
Village & Frequency & Percent & Cumulative Percent \\
\hline Turawa & 22 & 15.7 & 15.7 \\
Rahama & 37 & 26.4 & 42.1 \\
Maigana & 25 & 17.9 & 60.0 \\
Kinkiba & 23 & 16.4 & 76.4 \\
Danwata & 33 & 23.6 & 100.0 \\
Total & $\mathbf{1 4 0}$ & $\mathbf{1 0 0 . 0}$ & \\
\hline
\end{tabular}

From Table 2, the five rural wards selected show that Rahama village being close to the biggest market, Soba, had the highest trip to Soba market 37 (26.4\%). Turawa had the lowest number of trips $22(15.7 \%)$, of the vehicle to the Soba market because it is farthest from Soba. Kinkiba had 23 (16.4\%) trips because it is closest to the major town, Zaria. Some farmers take their crops to Zaria with many markets and in session daily instead of the Soba market, which is not a daily market.

Table 3. Price comparison

\begin{tabular}{crrr} 
Price nature & Frequency & Percent & \multicolumn{2}{c}{ Cumulative Percent } \\
\hline Expansive & 60 & 42.9 & 42.9 \\
Same & 53 & 37.9 & 80.8 \\
Cheap & 27 & 19.2 & 100.0 \\
Total & $\mathbf{1 4 0}$ & $\mathbf{1 0 0 . 0}$ & \\
\hline
\end{tabular}

From Table 3, sixty 60 (42.9\%) interviewees say transport fare across the study area is expansive. This might be due to the fact that large parts of the roads are in deplorable condition. There is continuous wear and tear of vehicle parts. This makes transporters increase the transport fare. Also, few people that sometimes ply roads could be responsible for the high transport fare because vehicle owners want to get profit from their investments. 53 (37.9\%) interviewees do not see any difference in the transport fare with urban areas like Zaria and Jos, which are along the major road or trunk A road that passes through the Local Government Area. See Figure 2. In contrast, 27 (19.2\%) say the transport fare is not expensive. These interviewees might be from some users of the lorry which is often cheaper than other transport means.

Table 4. Vehicle condition

\begin{tabular}{crrrr} 
Condition & \multicolumn{2}{c}{ Frequency } & Percent & Cumulative Percent \\
\hline Good & 34 & 24.3 & 24.3 \\
Fair & 47 & 33.6 & 57.9 \\
Bad & 59 & 42.1 & 100.0 \\
Total & $\mathbf{1 4 0}$ & $\mathbf{1 0 0 . 0}$ & \\
\hline
\end{tabular}


From Table 4, the condition of vehicles used for transportation across the Local Area is not good. Only $34(24.3 \%)$ interviewees say the vehicles are good. However, 47 (33.6\%) say they are fair, while $59(42.1 \%)$ see the vehicles as being bad. The poor condition of roads might have contributed to the bad shape of the majority of vehicles. Also, those with new vehicles are afraid to ply the roads when they are newly brought or bought.

Table 5. Type of vehicle used

\begin{tabular}{clrrr} 
Means & \multicolumn{2}{c}{ Frequency } & Percent & Cumulative Percent \\
\hline & Bus & 41 & 29.3 & 29.3 \\
& Lorry & 76 & 54.3 & 83.6 \\
Taxi & 23 & 16.4 & 100.0 \\
Total & $\mathbf{1 4 0}$ & $\mathbf{1 0 0 . 0}$ & \\
\hline
\end{tabular}

From Table 5, most of the interviewees, 76 (54.3\%) use lorry to evacuate their farm produces from farms to houses and markets. This is because it has a large capacity that can take both goods and passengers with ease and at the same time. Not only in Soba Local Government Area but many agricultural areas in Nigeria also use this type of vehicle because of this dual purpose. On the other hand, only $23(16.4 \%)$ of the interviewees say taxi is used to convey passengers in the local area mainly to the major market in Soba.

Table 6. Access to commercial transport

\begin{tabular}{|c|c|c|c|}
\hline Access to commercial transport & Frequency & Percent & Cumulative Percent \\
\hline Any time of the day & 53 & 37.9 & 37.9 \\
\hline Once a day & 48 & 34.3 & 72.9 \\
\hline $\begin{array}{l}\text { Once a week } \\
\text { Total }\end{array}$ & $\begin{array}{r}39 \\
140\end{array}$ & $\begin{array}{r}27.1 \\
\mathbf{1 0 0 . 0}\end{array}$ & 100.0 \\
\hline
\end{tabular}

From Table 6, only $53(37.9 \%)$ of the interviewees say they have access to transport any time of the day. This shows the deplorable condition that paralyzes trade and other socio-economic activities. Some interviewees, $39(27.1 \%)$ say they have access to transport only once a week. This means they normally wait until the market day, normally once a week, however the emergency. Families in need of medical attention in urban areas suffer more.

Table 7. Waiting time

\begin{tabular}{lrrr} 
Waiting Time & Frequency & Percent & Cumulative Percent \\
\hline Less than 15 Minutes & 9 & 6.4 & 6.4 \\
& & & 15.7 \\
16-30 Min & 13 & 9.3 & 100.0 \\
31- and above & 118 & 84.3 & \\
Total & $\mathbf{1 4 0}$ & $\mathbf{1 0 0 . 0}$ & \\
\hline
\end{tabular}

From Table 7, one hundred and eighteen $118(84.3 \%)$ of the interviewees say they wait for more than 31 minutes before they could get the vehicle to their various places of business. This shows how productivity and businesses are affected through time wastage. 
Table 8. Vehicle use from house to motor-able road

\begin{tabular}{crrr} 
Type of Vehicle & Frequency & Percent & Cumulative Percent \\
\hline Motorcycle & 66 & 47.1 & 47.1 \\
Tricycle & 19 & 13.6 & 60.6 \\
Bicycle & 65 & 46.4 & 100.0 \\
Total & $\mathbf{1 4 0}$ & $\mathbf{1 0 0 . 0}$ & \\
\hline
\end{tabular}

From Table 8, the interviewees are almost tied between riders of motorcycle and bicycle. None of the interviewees walk for a long distance, as indicated on the table. This shows a little bit sign of prosperity among the rural dwellers. This further indicates that despite the poor condition of the road, non-motorized vehicles can be used.

Table 9. Seasonality of roads

\begin{tabular}{crrrr} 
Season & Frequency & Percent & Cumulative Percent \\
\hline Dry & 38 & 27.1 & 27.1 \\
Rainy & 1 & 0.7 & 27.8 \\
All season & 101 & 72.2 & 100.0 \\
Total & $\mathbf{1 4 0}$ & $\mathbf{1 0 0 . 0}$ & \\
\hline
\end{tabular}

From Table 9, the roads are not in good shape that up to 38 (27.1) interviewees say some roads are seasonal and are only motorable during the dry season. This is serious considering that $27 \%$ is more than one quarter.

\section{Hypothesis testing}

Table 10: Pearson Product Moment Correlation Coefficient on impact of good transportation network and economic development

\begin{tabular}{llcccc} 
Variables & $\mathbf{N}$ & Mean & SD & r & P \\
\hline $\begin{array}{l}\text { Good } \\
\text { transport }\end{array}$ & 140 & 33.2 & 4.1 & -.671 & .0001 \\
$\begin{array}{l}\text { network } \\
\begin{array}{l}\text { Economic } \\
\text { dev. }\end{array}\end{array}$ & 140 & 19.7 & 3.4 & & \\
\hline
\end{tabular}

Table 10 reveals that a significant inverse relationship exists between a good transportation network and economic development in Soba Local Government Area of Kaduna State r=-.671 and p=.0001. This is because the p-value .0001 is less than 0.05 level of significance. The correlation coefficient reveals that the poor the transportation network, the lower the economic development in Soba Local Government of Kaduna State and vice-versa. Thus, the hypothesis which states that there is no significant impact of good transportation network on economic development of Soba Local Government of Kaduna State is hereby rejected.

\section{Conclusion}

This study examined the nature of rural transport challenges in the Soba Local Government Area, determine the current means of transportation used in the study area, examine the time taking to transport farm product from the rural settlement to Soba central market and determine the road characteristics and condition in the study area. The study found the condition of roads in the area as bad and some of them are not even accessible. The study also revealed that the poor the transportation 
network, the lower the economic development in Soba Local Government of Kaduna State and viceversa. Despite the poor nature of the roads, people still transact, although productivity is greatly affected.

\section{Recommendations}

Based on the issues highlighted and the overall findings, it can be recommended that; as a matter of priority and to improve the economy and general productivity of the area, the government should make an effort towards improving the quality of the existing connectivity of roads and their period of motor ability as some of the roads are seasonal. The intervention of the government should involve increasing and provision of more accessible roads, increasing the width of the existing roads and provision of culverts and drainages to increase the free flow of traffic. This will help achieve SDGs goal 9 and 11 with their multiplier effects which are building resilient infrastructure, promoting of inclusiveness and sustainable industrialization and foster innovation, and making cities and human settlements inclusive, safe, resilient and sustainable.

\section{References}

Adedeji, O.A., Olafiaji, E.M., Omole, F.K., Olanibi, J. A. and Yusuf, L. (2014). An assessment of the impact of rural development: a case study of Obokun Local Government Area of Osun State, Nigeria. British Journal of Environmental Sciences, 2(1), 34-48.

Aderamo, A. J. And Magaji, S. A. (2010). Rural transportation and the distribution of public facilities in Nigeria: a case of Edu Local Government Area of Kwara State. Journal of human ecology, 29(3).

Banjo, G., Gordon, H., and Riverson, J, (2012). Rural transport, improving its contribution to growth and poverty reduction in Sub-Saharan Africa, Working Paper No. 93. World Bank, Washington, DC.

Cook, J. R., Huizenga, C., Petts R., Sampson, L. R., Visser, C. and Yiu, A. (2017). Rural transport research in support of Sustainable Development Goals. Transport and Communications Bulletin for Asia and the Pacific. 87.

Economic and Social Commission for Asia and the Pacific [ESCAP] and United Nations (2019). Enhancing rural transport connectivity to regional and international transport networks in Asia and the Pacific. Monograph series on sustainable and inclusive transport.

Faiz, A. Faiz, A., Wang, W., Bennet, C. (2012). Sustainable rural roads for livelihoods and livability. Procedia - Social and Behavioural Sciences 53, 1-8. SIIV 5th International Congress Sustainability of Road Infrastructures.

Geography Department, Federal College of Education, Zaria (undated).

Krejie and Morgan (1970). determining sample size for research activities. Educational and Psychological Measurement, 30, 607-610.

Mc Kenna, M. (2006). A case on the impact of rural transport provision on older people in one rural area. An undergraduate thesis, NUI.

Perz, S. G., Xia, Y., \& Shenkin, A. (2014). Global integration and local connectivity: trans- boundary highway paving and rural-urban ties in the South Western Amazon. Journal of Latin American Geography, 13(3), 205-239.

Rodrigue, J. P., Comtois, C., and Slack, B. (2017). The geography of transport systems, New York: Routledge.

Starkey, P. and Hine, J. (2014). Poverty and sustainable transport: how transport affects poor people with policy implications for poverty reduction. London: ODI.

United Nations Centre for Regional Development (2017). Vientiane Declaration on Sustainable Rural Transport towards Achieving the 2030 Agenda for Sustainable Development.

Vasconcellos, E. A. (1997). Rural transport and access to education in developing countries: policy issues. Jounal of Transport Geography, 5(2), 127-136.

Witkiss, M., Hine, J. L. and Ellis, S. D. (2001). The provision of rural transport services: an agenda for reform (Rural transport knowledge base rural travel and transport program).

Works Department Soba Local Government Historical Document, undated.

World Bank (2006). Measuring rural access. World Bank Document. World Bank Group. Documents.worldbank.org. 
Yap, K. S. (2019). Peri-urban transformations in Southeast Asia”. Chapter 2 in Padawangi, R. (Ed). Routledge Handbook of Urbanisation in Southeast Asia. 